\title{
Concussion Induced Electrocardiogram Changes
}

\author{
Michael T Flannery
}

\begin{abstract}
A middle aged male presented to the Emergency room with presyncope following a hockey induced concussion. Abnormal electrocardiogram changes combined with a strong family history resulted in a cardiac catheterization which was normal. Nearly 2 years later, flattening of the $\mathrm{T}$ waves persisted with symptoms. Three years later, the patient developed ALS with predominant upper motor neuron findings.
\end{abstract}

Keywords: Concussion; Closed brain injury; Abnormal electrocardiogram; Lou Gehrig's disease (ALS)

\section{Introduction}

Concussion injuries in sports have received increased attention in prevention not only due to acute and sub-acute symptoms but potentially long-term effects of brain injury including typical features of closed brain injury especially when recurrent. These may include loss of cognitive function effecting activities of daily living similar to dementia. More recently, there are concerns of amyotrophic lateral sclerosis (ALS) or Lou Gehrig's disease due to recurrent concussions. There are many findings in concussions and our case reviews some of the electrocardiogram changes seen with acute injury. These changes are typically not followed over time and patients may not remember to relate new symptoms to their prior injury.

Manuscript accepted for publication June 6, 2013

Department of Internal Medicine, University of South Florid Morsani College of Medicine, 12901 Bruce B. Downs Blvd., MDC Box 19, Room L1041, Tampa, FL 33612, USA.

Email: mflann5555@aol.com

doi: http://dx.doi.org/10.4021/jmc1338w

\section{Case Report}

A 46-year-old male presented with pre-syncope stating he had struck his head against the ice rink board 2 days previously with some residual headache. His history included a prior concussion at age 12 and a reported normal electrocardiogram (ECG) in 1986 (baseline). The patient was, otherwise, asymptomatic. A complete exam, laboratory studies with cardiac isoenzmes and a computed tomography of the head were normal. An ECG was performed as shown in Figure 1 which demonstrated inverted $\mathrm{T}$ waves in V1-V5 and flattening of the T waves in V6, III and aVf and an incomplete right bundle branch block (QRS, $110 \mathrm{~ms}$ ). Given a strong family history, the patient underwent cardiac catheterization which was normal. The patient reported post-concussion symptoms for 3 months, after the incident, including headache and presyncope. A subsequent ECG was performed at 28 months later (Fig. 2), which showed mild flattening of the $\mathrm{T}$ waves (QRS, $100 \mathrm{~ms}$ ).

\section{Discussion}

Concussions causing ECG abnormalities are rarely discussed but have been reported with similar findings [1,2]. Finally, our patient was diagnosed, 4 years later, with amyotrophic lateral sclerosis which controversially may be associated with head trauma [3-5]. The patient resented with predominately upper motor signs and symptoms such as muscle spasm and hyperreflexia which offer better prognostic findings in the setting of ALS. Given the fact that such long-term side effects can be devastating and life threatening, attention should be focused on prevention and then appropriate diagnosis and treatment which typically involve a lengthy period of inactivity from sports which is obviously frustrating to the sports player. Patients should be honest and forthcoming regarding concussion like symptoms that may persist such as headaches, pre-syncope, ringing in the ears and a sense of imbalance. Without special attention to subsequent prevention, patients may develop more serious long-term effects as previously described. The electrocardiographic changes, as 


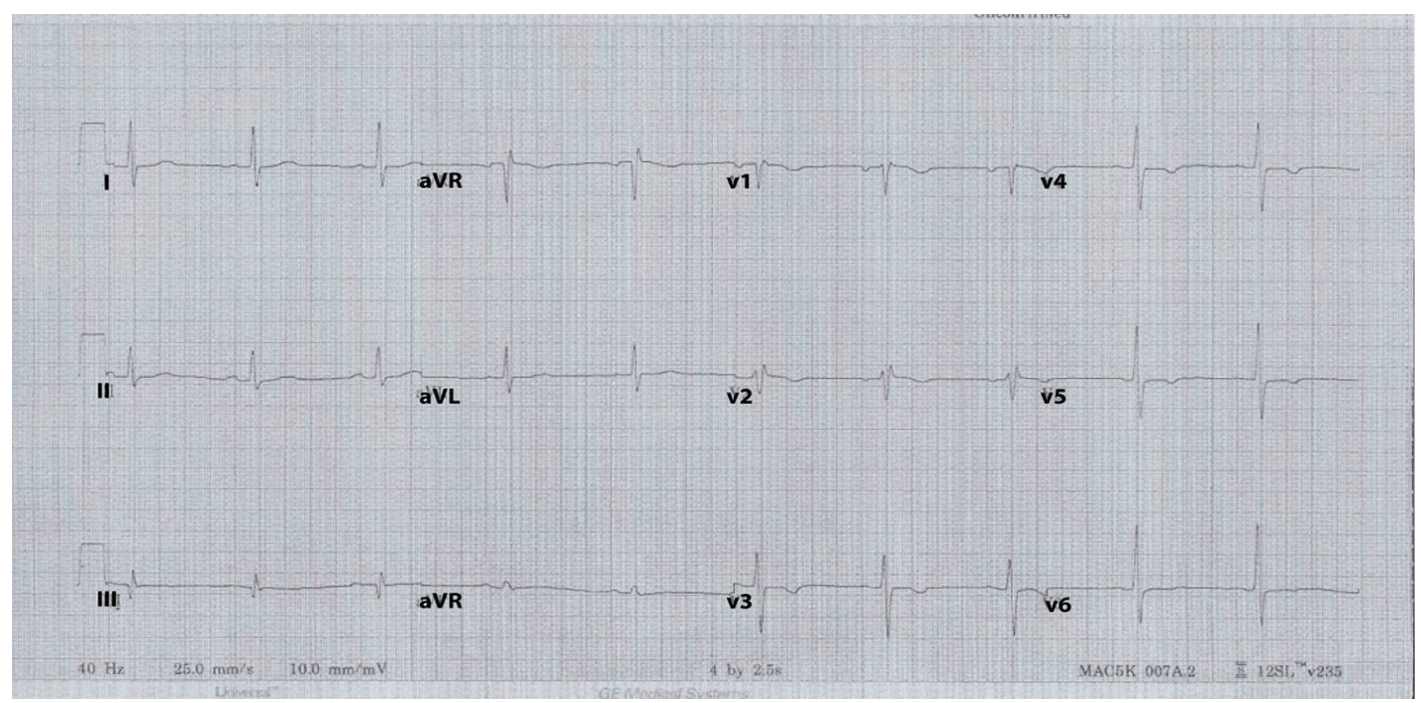

Figure 1. ECG at time of incident demonstrating fairly diffuse T wave inversions.

seen in this case, should serve as a reminder to the caring physician, so that unnecessary invasive procedures will not be performed potentially putting the patient at additional serious risks including hematoma, bleeding and infection with the occasional death due to rhythm disturbances or cardiac wall penetration causing tamponade physiology.

\section{References}

1. Ommaya AK. Trauma to the nervous system. Ann R Coll Surg Engl. 1966;39(6):317-347.

2. Greenspahn BR, Barzilai B, Denes P. Electrocardio- graphic changes in concussion. Chest. 1978;74(4):468469.

3. DeKosky ST, Ikonomovic MD, Gandy S. Traumatic brain injury--football, warfare, and long-term effects. N Engl J Med. 2010;363(14):1293-1296.

4. Bedlack RS, Genge A, Amato AA, Shaibani A, Jackson $\mathrm{CE}$, Kissel JT, Wall C, et al. Correspondence regarding: TDP-43 proteinopathy and motor neuron disease in chronic traumatic encephalopathy. J Neuropathol Exp Neurol 2010:69;918-29. J Neuropathol Exp Neurol. 2011;70(1):96-97; author reply 98-100.

5. Bartholet J. The collision syndrome. Sci Am. 2012;306(2):66-71.

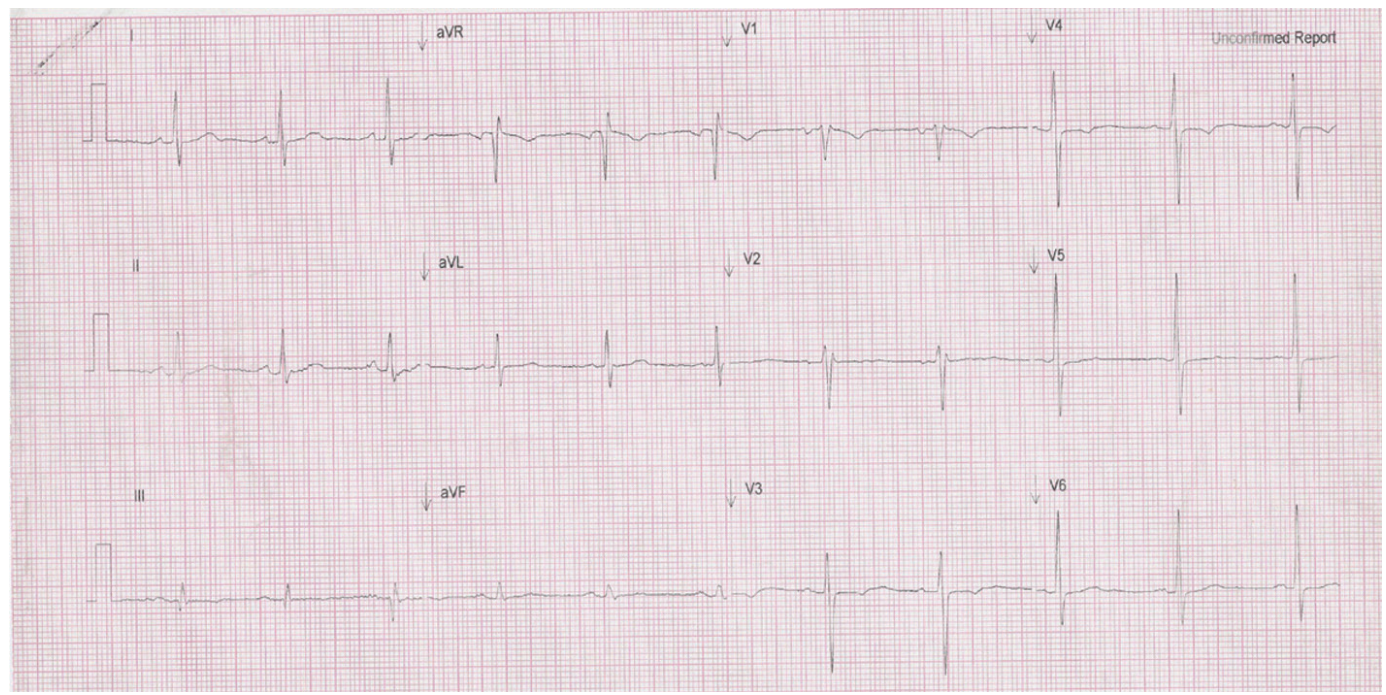

Figure 2. Routine follow-up ECG 28 months later which still shows some T wave changes that have not resolved to a normal state. 